\title{
SOC storage and potential of grasslands from 2000 to 2012 in central and eastern Inner Mongolia, China
}

\author{
TIAN Zheng ${ }^{1}$, WU Xiuqin ${ }^{1 *}$, DAI Erfu' ${ }^{2}$, ZHAO Dongsheng ${ }^{2}$ \\ ${ }^{1}$ Yanchi Research Station, College of Soil and Water Conservation, Beijing Forestry University, Beijing 100083, China; \\ ${ }^{2}$ Institute of Geographic Sciences and Natural Resources Research, Chinese Academy of Sciences, Beijing 100101, China
}

\begin{abstract}
Grassland ecosystem is an important component of the terrestrial carbon cycle system. Clear comprehension of soil organic carbon (SOC) storage and potential of grasslands is very important for the effective management of grassland ecosystems. Grasslands in Inner Mongolia have undergone evident impacts from human activities and natural factors in recent decades. To explore the changes of carbon sequestration capacity of grasslands from 2000 to 2012, we carried out studies on the estimation of SOC storage and potential of grasslands in central and eastern Inner Mongolia, China based on field investigations and MODIS image data. First, we calculated vegetation cover using the dimidiate pixel model based on MODIS-EVI images. Following field investigations of aboveground biomass and plant height, we used a grassland quality evaluation model to get the grassland evaluation index, which is typically used to represent grassland quality. Second, a correlation regression model was established between grassland evaluation index and SOC density. Finally, by this regression model, we calculated the SOC storage and potential of the studied grasslands. Results indicated that SOC storage increased with fluctuations in the study area, and the annual changes varied among different sub-regions. The SOC storage of grasslands in 2012 increased by $0.51 \times 10^{12} \mathrm{~kg} \mathrm{C}$ compared to that in 2000 . The average carbon sequestration rate was $0.04 \times 10^{12} \mathrm{~kg} \mathrm{C} / \mathrm{a}$. The slope of the values of SOC storage showed that SOC storage exhibited an overall increase since 2000, particularly for the grasslands of Hulun Buir city and Xilin Gol League, where the typical grassland type was mainly distributed. Taking the SOC storage under the best grassland quality between 2000 and 2012 as a reference, this study predicted that the SOC potential of grasslands in central and eastern Inner Mongolia in 2012 is $1.38 \times 10^{12} \mathrm{~kg} \mathrm{C}$. This study will contribute to researches on related methods and fundamental database, as well as provide a reference for the protection of grassland ecosystems and the formulation of local policies on sustainable grassland development.
\end{abstract}

Keywords: vegetation cover; soil organic carbon potential; soil organic carbon storage; carbon sequestration; MODIS data

Citation: TIAN Zheng, WU Xiuqin, DAI Erfu, ZHAO Dongsheng. 2016. SOC storage and potential of grasslands from 2000 to 2012 in central and eastern Inner Mongolia, China. Journal of Arid Land, 8(3): 364-374. doi: 10.1007/s40333-016-0041-8

The global carbon cycle is a crucial factor that affects the global climate (Friedlingstein et al., 2001). Pedosphere is one of the important carbon sinks in the terrestrial ecosystems. Within 1-m depth of the topsoil layer, carbon storage is prioritized over organic carbon (Sombroek et al., 1993). The soil organic carbon (SOC) storage in the topsoil layer is 1.5 times that of the total carbon storage in the existing natural vegetation and crops (Sombroek et al., 1993; Grace, 2004; Lal, 2004). The amount of organic carbon stored in soil is controlled by natural factors, such as

\footnotetext{
*Corresponding author: WU Xiuqin (E-mail: wuxq@bjfu.edu.cn)

Received 2015-08-14; revised 2015-11-12; accepted 2015-12-10

(C) Xinjiang Institute of Ecology and Geography, Chinese Academy of Sciences, Science Press and Springer-Verlag Berlin Heidelberg 2016
} 
parent material, climate, topography and land cover, as well as human-induced factors associated with land use (Schils et al., 2008; Piñeiro et al., 2010). Moreover, an important part of the missing atmospheric carbon sink is highly likely to come from the soil carbon reservoir (Schimel et al., 2001). Hence, a small variation in SOC would cause global climate change (Krogh et al., 2003). Therefore, a clear comprehension of SOC storage and potential is beneficial not only for the protection of ecosystems but also for understanding the problems of ecosystems, thus facilitating the adjustment of management practices.

Grassland ecosystem is an important part of the terrestrial carbon cycle system (Scurlock and Hall, 1998). Areas of global grasslands account for approximately $25 \%$ of the total global land area, and the SOC storage of grasslands accounts for roughly $20 \%$ of the total SOC storage of global land (Jobbágy and Jackson, 2000). Variations in carbon storage of grasslands would significantly affect climate changes, although they may occur slowly (Parton et al., 1995). Total area of grasslands in China is approximately $4 \times 10^{8} \mathrm{hm}^{2}$, accounting for $12.5 \%$ of the total grassland area in the world (Liao and Jia, 1996). These grasslands are primarily distributed in northern and western China. Grasslands in the northern temperate zone are a major component of grasslands in China, occupying approximately $78 \%$ of the total area of grasslands (Chen and Wang, 2000). Grasslands in Inner Mongolia have seriously degenerated between the 1980s and the 1990s because of overgrazing, unplanned and unscientific land reclamations, and mining activities. In the 1980s, the degraded grassland area in the key pastoral areas of northern Inner Mongolia accounted for $39.7 \%$ of the total grassland area. By the mid-1990s, the area of degraded grasslands accounted for roughly half of the total grassland area ( $\mathrm{Du}, 2006)$. Grassland degradation will directly affect SOC storage, soil fertility and microbial biomass (Huang et al., 2010; Liu et al., 2015).

The protection of grassland resources was initiated at the onset of the $21^{\text {st }}$ century; therefore, grasslands in Inner Mongolia recovered gradually from degradation (Li et al., 2012). The recovery of grasslands began to accelerate from 2005 to 2009. At the same time, the areas of farmland and desert started to shrink (Hu et al., 2012). From 2000 to 2007, the SOC storage of grasslands in Xilin Gol League increased from 20.85 to $29.80 \mathrm{Tg}$ (Fu et al., 2011). The existing biogeochemical models and mathematical methods are commonly used to study the SOC storage (Molina et al., 1983; Li et al., 1992; Mueller et al., 1996; Luo et al., 2015). The biogeochemical models are also used in predicting SOC dynamics (Qiu et al., 2003). The SOC sequestration rate and its potential in the grassland ecosystems of China were estimated using the interpolation method (Guo et al., 2008). Land use conversion is an important factor usually used to estimate SOC storage ( $\mathrm{Lu}$ et al., 2015), and it is strongly affected by human activity and social change factors. The long-term effects of climate change on SOC storage was also explored in most areas of Inner Mongolia (Zhao et al., 2015). The change in the SOC storage is a complex process, and this process is affected by environmental factors. However, these methods mentioned above typically ignore the environmental conditions. Vegetation is an important environmental factor that affects SOC storage (Long et al., 1989). In this study, we used vegetation growth indices combined with the MODIS data to estimate the SOC storage and potential of grasslands in Inner Mongolia. This study integrated the vegetation growth conditions with the actual situation of SOC density and storage to calculate the SOC storage and potential in Inner Mongolia grasslands. This study will provide a reference on related methods and fundamental database.

\section{Study area and data analysis}

\subsection{Study area}

The study area is located in central and eastern Inner Mongolia of China (Fig. 1) and has an area of $335,719 \mathrm{~km}^{2}$, accounting for $55 \%$ of the total area of Inner Mongolia. Inner Mongolian grassland belongs to the typical mid-latitude semi-arid temperate grassland ecosystem (Dong et al., 2000). Geographically, the study area includes three climatic zones, i.e. sub-humid, semi-arid and arid ones. Precipitation mainly occurs in summer and reduces gradually from east to west. 
Three types of grasslands are distributed in the study area from east to west. They are meadow grassland, typical grassland and desert grassland (Xu, 2004; Ma et al., 2006). Meadow and typical grasslands, located in eastern Inner Mongolia, are dominated by Leymus chinensis, Stipa grandis and Stipa baicalensis. The soil types are usually dark chestnut soil and typical chestnut soil. Although typical grassland is the major type in the middle part, the species of $S$. grandis is replaced by Stipa krylovii because of the lack of precipitation. The most common dominant species are Cleistogenes songorica, Stipa breviflora and Allium mongolicum. The soil types are mainly gray desert soil and aeolian sandy soil (Yang et al., 2012).

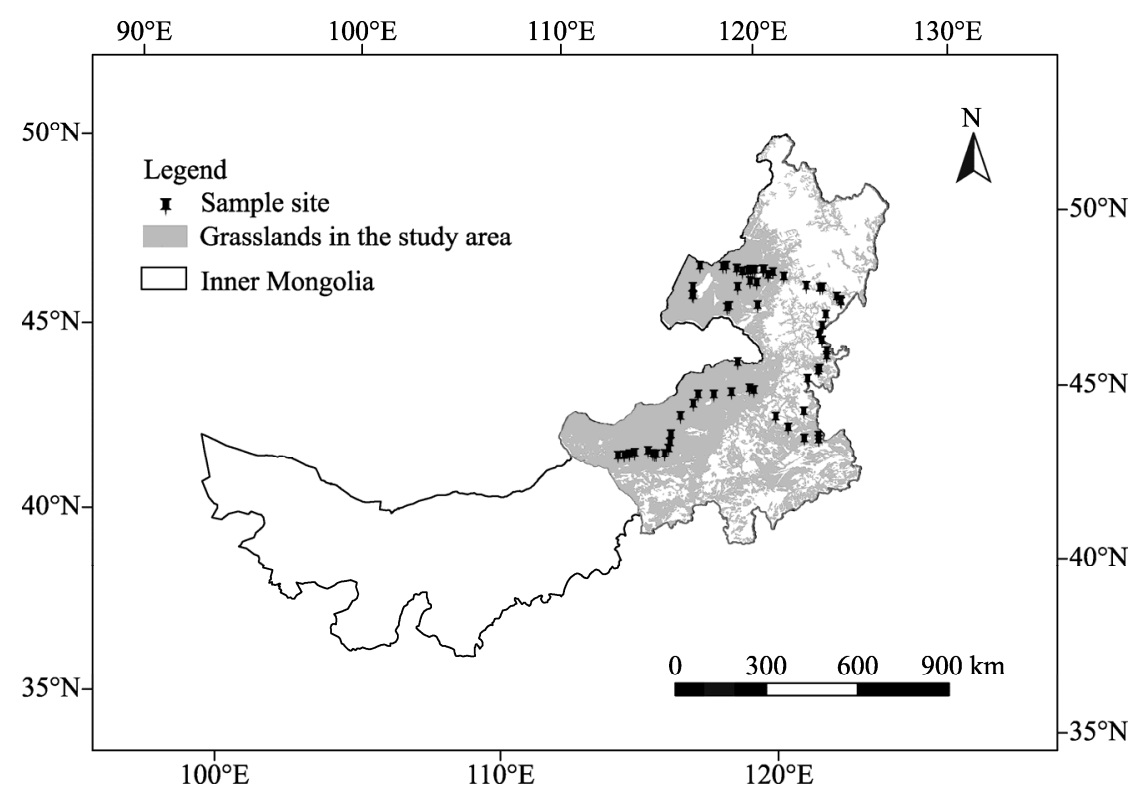

Fig. 1 Map of the study area and locations of sample sites in central and eastern Inner Mongolia

\subsection{Field investigation and sampling}

In June 2012, 65 sample sites and 195 quadrats (3 parallel quadrats per sample site) were selected among different grassland types in central and eastern Inner Mongolia. These sample sites were divided into two groups. Fifty-two sample sites (i.e. 156 quadrats) were used to build the regression models, and the other 13 sample sites (i.e. 39 quadrats) were used to test the accuracy of models. The area of each site was $10 \mathrm{~m} \times 10 \mathrm{~m}$ and the area of each quadrat was $0.5 \mathrm{~m} \times 0.5 \mathrm{~m}$. All of the grasses above the ground in each quadrat were cut and bagged, and then dried to constant weight at $65^{\circ} \mathrm{C}$ in the laboratory. Plant heights were simultaneously measured during field investigations. In each parallel quadrat, the heights of 5 random constructive species were measured. The plant height of each sample site was the average of the three parallel samples. Soil samples were collected within $20-\mathrm{cm}$ depth of the topsoil layer. Three parallel samples were collected in each site. The SOC content and soil bulk density of each sample site were also the averages of the three parallel samples. The SOC content was measured using the potassium dichromate oxidation titration method and the soil bulk density was measured using the ring sampler method.

\subsection{Data sources and processing}

The enhanced vegetation index (EVI) data used in this study were the half-month maximum EVI composite MODIS data with a spatial resolution of $250 \mathrm{~m} \times 250 \mathrm{~m}$, which were derived from the MOD13Q1 dataset from NASA. The EVI dataset included the data in the growing season (May to September) of 2000-2012, comprising 130 images. The annual maximum EVI gray-value images of each year were obtained using the maximum value composite method.

The distribution of grasslands in the study area was derived from the 1:100,000 land use map in 2012 combined with the 1:1,000,000 Chinese vegetation map from the Scientific Information 
Center for Resources and Environment, Chinese Academy of Sciences. We determined the classification of grassland types according to the study of Xu (2004). All of these processes were implemented in Erdas 9.2 and ArcGIS 10.0.

\subsection{Vegetation cover, aboveground biomass and plant height}

In this study, vegetation cover was estimated via the extensively utilized dimidiate pixel model (Purevdorj et al., 1998). The principle of this model is to regard a pixel as a mixed pixel consisting of vegetation and soil $(\mathrm{Li}, 2011)$. The vegetation cover is calculated as follows:

$$
\mathrm{f}_{\mathrm{c}}=\left(\mathrm{EVI}-\mathrm{EVI}_{\text {soil }}\right) /\left(\mathrm{EVI}_{\mathrm{veg}}-\mathrm{EVI}_{\text {soil }}\right) \text {. }
$$

Where, $f_{c}$ is the vegetation cover, $E I_{v e g}$ is the value of the pixel totally covered by vegetation, and $\mathrm{EVI}_{\text {soil }}$ is the value of the pixel without vegetation (bare soil).

Pixels were totally covered by vegetation and bare soil in the study area. Hence, EVI $_{\text {soil }}$ and $\mathrm{EVI}_{\text {veg }}$ could theoretically approximate the values of the minimum and maximum EVI, respectively. However, the actual values of $\mathrm{EVI}_{\text {soil }}$ and $\mathrm{EVI}_{\mathrm{veg}}$ slightly vary under different time, space and environmental conditions (Carlson and Ripley, 1997). We used the confidence regions to determine the $\mathrm{EVI}_{\text {soil }}$ and $\mathrm{EVI}_{\mathrm{veg}}$. Given that the confidence region was an experimental value, we selected the most commonly used region in a similar study from $0.5 \%$ to $99.5 \%$ (Wu et al., 2012 ) as the confidence region of this study. $\mathrm{EVI}_{\text {soil }}$ and $\mathrm{EVI}_{\mathrm{veg}}$ were the minimum and maximum values in the confidence regions, respectively.

Based on sample data collected in June 2012 and EVI data of June 2012, we established the regression models between EVI and aboveground biomass and between EVI and plant height to estimate the aboveground biomass and plant height of the study area from 2000 to 2012 .

\subsection{Grassland evaluation index}

The comprehensive evaluation index of grasslands reflects the degree of grassland degradation (Li and Liu, 2004). In this study, it was calculated by the weighted comprehensive assessment of vegetation cover, aboveground biomass and plant height of grasslands in the study area. Taking the grassland comprehensive evaluation index ( $\mathrm{Li}$ and Liu, 2004) and grassland degradation index (Gao et al., 2006; Wen et al., 2010) as references, we selected three most representative factors (i.e. aboveground biomass, plant height and vegetation cover) to establish the grassland evaluation index (Eq. 2).

$$
\mathrm{GEI}=\sum_{i=1}^{3} f_{i} w_{i} .
$$

Where, GEI is the grassland evaluation index, $f_{i}$ represents the value of each factor (aboveground biomass, plant height and vegetation cover), and $w_{i}$ is the weight of each factor.

In the factor analysis process, the commonality of the factor could be expressed by the common variance of the factor. Calculating the weight of each factor in comprehensive assessment by the normalized processing of variable commonality is scientifically reasonable for the representation of the variables on each factor evaluation. In this study, we adopted the factor analysis method (Li, 2002) to calculate the weight of each factor (Eq. 3).

$$
w_{i}=\sum_{j=1}^{3} W_{j i} P_{j} / \sum_{j, i=1}^{3} W_{j i} P_{j} .
$$

Where, $w_{i}$ is the weight of each factor $(i=1,2,3), W_{j i}$ is the value in the component score coefficient matrix, and $P_{j}$ is the value of variance contribution for each factor $(j=1,2,3)$. The weights of aboveground biomass, plant height and vegetation cover $(0.35,0.35$ and 0.30 , respectively) were calculated using the SPSS 18.0 software.

\subsection{Calculation of SOC density and storage}

SOC density refers to the organic carbon storage in a certain soil depth of unit area, and SOC storage refers to the total SOC in the region. In this study, soil samples were collected at depth of 0-20 cm. The formulas of SOC density and storage are as Eqs. 4 and 5, respectively (Batjes, 
1996):

$$
\mathrm{SOC}_{\mathrm{d}}=\mathrm{C} \times \theta \times \mathrm{H} \times(1-\delta) / 100, \quad(4) ; \quad \mathrm{SOC}_{\mathrm{s}}=\mathrm{SOC}_{\mathrm{d}} \times \mathrm{D} .
$$

Where, $\mathrm{SOC}_{\mathrm{d}}$ is the SOC density $\left(\mathrm{kg} \mathrm{C} / \mathrm{m}^{2}\right), \mathrm{C}$ is the SOC content $(\mathrm{g} / \mathrm{kg}), \mathrm{H}$ is the soil depth $(\mathrm{cm})$, $\theta$ is the soil bulk density $\left(\mathrm{g} / \mathrm{cm}^{3}\right), \delta$ is the volume percentage of gravel diameter larger than $2 \mathrm{~mm}$, $\mathrm{SOC}_{\mathrm{s}}$ is the SOC storage $(\mathrm{kg} \mathrm{C})$, and $\mathrm{D}$ is the area of the study region $\left(\mathrm{m}^{2}\right)$. The percentage volume of gravel with diameter larger than $2 \mathrm{~mm}$ in Inner Mongolia was $9.36 \%$, which was derived from the records of 491 soil samples in a similar study in Inner Mongolia (Yang et al., 2012).

\subsection{Slope analysis of the values of SOC storage}

The unary linear regression equations can simulate the change trend of grids in a certain time series (Song and Ma, 2007), and the slope of the unary linear regression reflects the changing trend of the data series (Stow, 2003). In this study, if slope $>0$, then the change trend of EVI in 2000-2012 increased, otherwise it decreased.

$$
\text { Slope }=\frac{n \times \sum_{i=1}^{n} i \times M_{E V I, i}-\sum_{i=1}^{n} i \sum_{i=1}^{n} M_{E V I, i}}{n \times \sum_{i=1}^{n} i^{2}-\left(\sum_{i=1}^{n} i\right)^{2}} .
$$

Where, $i$ refers to the year $(i=2000,2001, \ldots, 2012)$, and $M_{E V I, i}$ denotes the maximum EVI value of each year.

\subsection{SOC potential estimation}

In this study, the SOC potential of a certain year is defined as the maximum SOC storage from 2000 to 2012 under the best grassland quality subtract the SOC storage of that year (Dai et al., 2015). The SOC potential can reflect the growth capacity of carbon sequestration in the future. The best grassland quality was obtained through the maximum value of grassland evaluation index from 2000 to 2012. Therefore, the SOC potential in 2012 was calculated by Eq. 7.

$$
\text { SOC potential }=\mathrm{SOC}_{\mathrm{s}(\mathrm{Max})}-\mathrm{SOC}_{\mathrm{s}(2012)} \text {. }
$$

Where, $\mathrm{SOC}_{\mathrm{s}(\operatorname{Max})}$ is the maximum value of SOC storage from 2000 to 2012 , and $\mathrm{SOC}_{\mathrm{s}(2012)}$ is the SOC storage of 2012 .

\section{Results}

\subsection{Regression models on SOC density}

Linear, power, logarithm, quadratic polynomial, cubic polynomial and exponential function models were selected as regression models in this study. Based on SPSS software, we obtained the best fit models through contrast analysis (Fig. 2). The determination coefficient $\left(R^{2}\right)$ and the average relative error (E) were obtained by the common accuracy verification methods. They were selected to verify the accuracy of the regression models. Generally, the regression model is more accurate when $R^{2}$ is higher. Additionally, the regression model is more accurate when the relative average error is smaller. Our results indicated that exponential, power and cubic polynomial function models are the best fit models for representing the relationships of aboveground biomass and EVI, plant height and EVI, and SOC density and grassland evaluation index, respectively.

\subsection{Changes of SOC storage between 2000 and 2012}

Based on the regression models, we obtained the SOC density and storage of each grassland type in each year from 2000 to 2012 by Eqs. 4 and 5, respectively (Fig. 3). The results indicated that the SOC storage of grasslands in the study area in 2012 increased by $0.51 \times 10^{12} \mathrm{~kg} \mathrm{C}$ compared to that in 2000. From 2000 to 2012, SOC storage was around the average value, and the interannual variation was irregular. The SOC storage increased steadily from 2009 to 2012.

The SOC sequestration rate could be regarded as the change in the SOC storage year by year or 
the average sequestration rate in 13 years. Between 2000 and 2012, the average SOC sequestration rate was $0.04 \times 10^{12} \mathrm{~kg} \mathrm{C} / \mathrm{a}$ in the study area. The highest SOC sequestration occurred from 2007 to 2008 , and the SOC storage increased by $0.77 \times 10^{12} \mathrm{~kg} \mathrm{C}$; while the lowest SOC sequestration occurred from 2008 to 2009 , and the SOC storage decreased by $0.77 \times 10^{12} \mathrm{~kg} \mathrm{C}$.
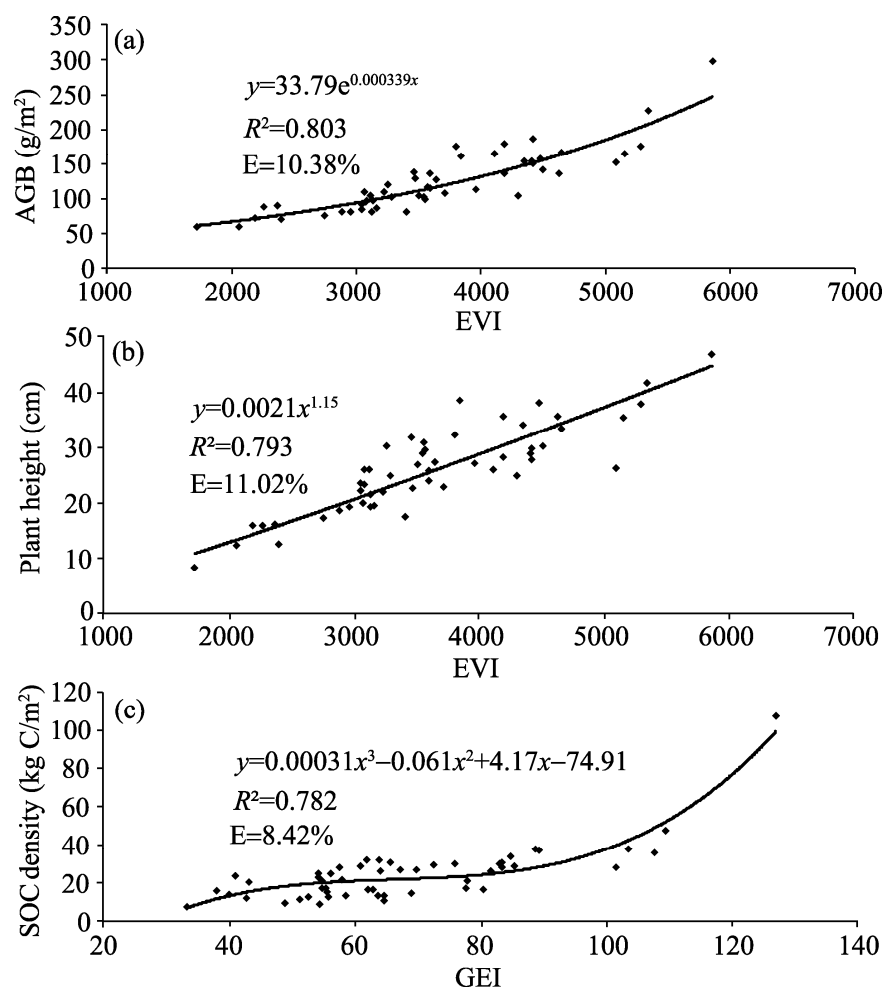

Fig. 2 Regression models for (a) aboveground biomass (AGB) and enhanced vegetation index (EVI), (b) plant height and EVI, and (c) SOC (soil organic carbon) density and GEI (grassland evaluation index). E, average relative error.

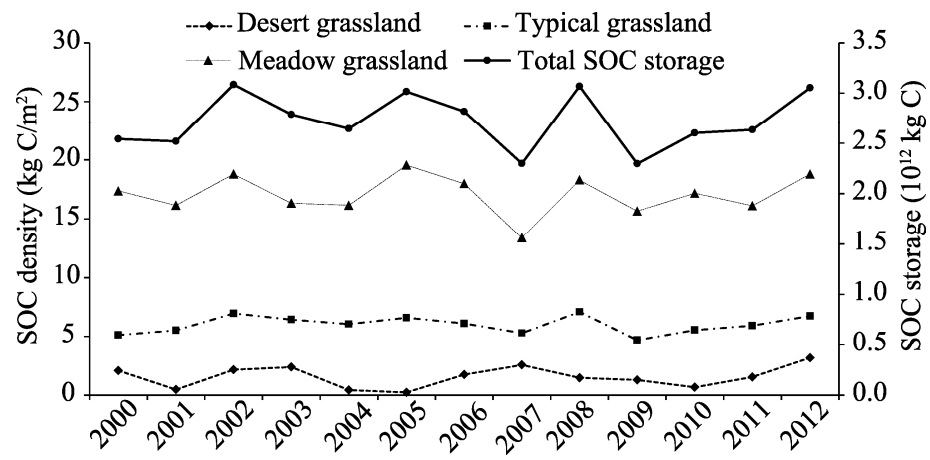

Fig. 3 SOC density in three grassland types and total SOC storage of grasslands from 2000 to 2012

\subsection{Slope analysis of the values of SOC storage}

In this study, slope represents the general changing tendency of SOC storage across the time series. A positive value implies that the overall change trend of SOC storage is increasing, while a negative value signifies that the overall change trend of SOC storage is decreasing. Based on the slope analysis of the values of SOC storage, we concluded that the SOC storage increased overall since 2000 (Fig. 4). The area of SOC storage increased accounted for $57.81 \%$ of the total study area, where the Hulun Buir grassland and Xilin Gol grassland are distributed; while the area of SOC storage decreased accounted for $42.19 \%$ of the total study area, where the Greater Hinggan Mountains are distributed. 


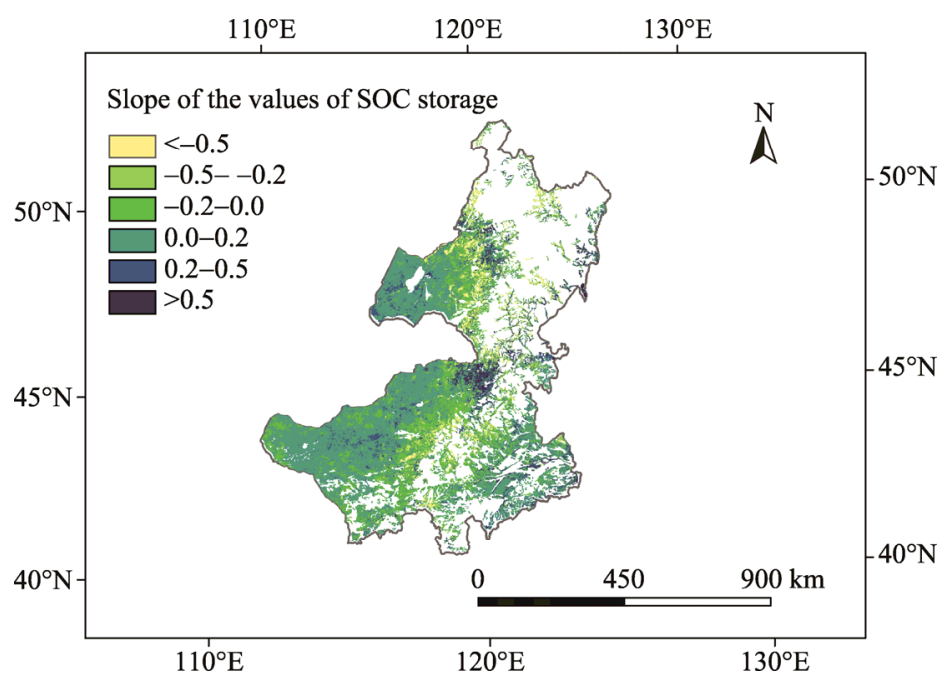

Fig. 4 Map of the slope of the values of SOC storage from 2000 to 2012

\subsection{Estimation of SOC potential}

Our results showed that the largest possible SOC storage in the study area was $4.43 \times 10^{12} \mathrm{~kg} \mathrm{C}$, and the SOC potential in 2012 was $1.38 \times 10^{12} \mathrm{~kg} \mathrm{C}$. At spatial scales, the SOC potential of different areas was dissimilar (Fig. 5). The SOC potential of grasslands in eastern Inner Mongolia was above $1.5 \mathrm{~kg} \mathrm{C} / \mathrm{m}^{2}$, which was significantly greater than that in the western region. Moreover, the regions with larger SOC potential were mainly distributed near the Greater Hinggan Mountains in the northeast part and on the west side of the Hulun Buir grassland and in the central area of the Xilin Gol grassland. However, the SOC potential was relatively low $\left(<1.5 \mathrm{~kg} \mathrm{C} / \mathrm{m}^{2}\right)$ in the western regions dominated by typical grasslands compared to that in the eastern area. The SOC potential was extremely low in the Sonid Left Banner region, which was mainly less than $0.1 \mathrm{~kg} \mathrm{C} / \mathrm{m}^{2}$.

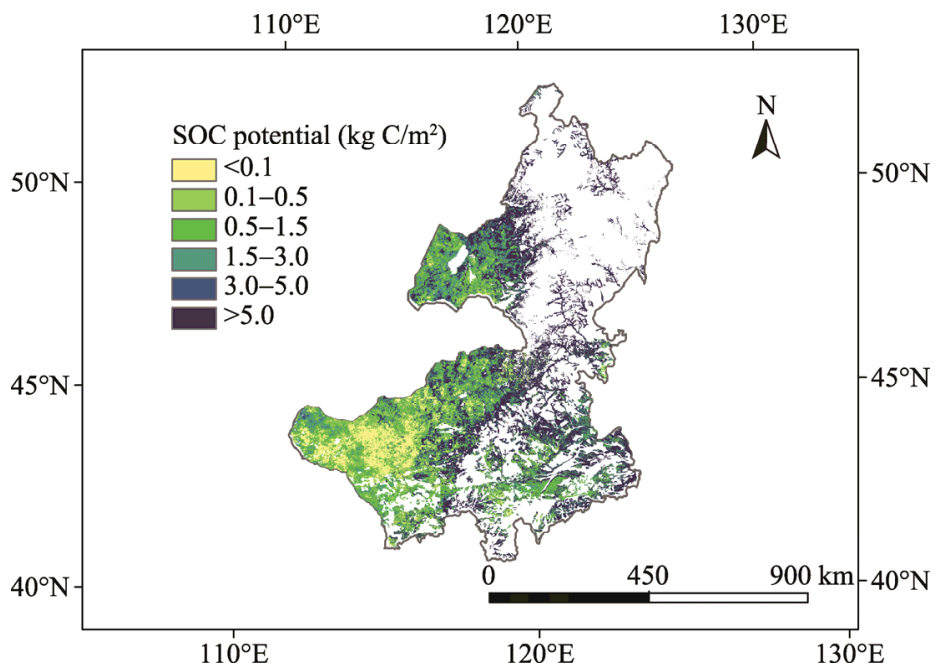

Fig. 5 Map of the SOC potential of grasslands in 2012

\section{Discussion}

The change in SOC storage is a complicated process, particularly at a large spatial scale. Therefore, some uncertainties existed in the prediction. In this study, the accuracy of the regression model between grassland evaluation index and SOC density was high (Fig. 2c). However, from the model test results, the positive error was higher than the negative error, which 
might result in the estimation value larger than the actual one. The gravel content in soil was one of the parameters in the calculation process of SOC density. In the study area, there are several soil types. The gravel contents of different soil types also varies, and the gravel content would affect the distribution of SOC storage in different soil types.

In the 1980s and 2011-2012, the SOC storage in Inner Mongolia grasslands was $2.05 \times 10^{12}$ and $2.17 \times 10^{12} \mathrm{~kg} \mathrm{C}$, respectively; and the average density was 3.48 and $3.69 \mathrm{~kg} \mathrm{C} / \mathrm{m}^{2}$, respectively (Dai et al., 2014). These values were all higher than the estimation values in our study. The disparity might be attributed to the different image data used in the two studies (i.e. NDVI image data in the study of Dai et al. (2014) and EVI image data in this study).

In the 1990s, grassland overgrazing in China substantially resulted in grassland degradation (Zou et al., 2002). However, since 2000, with the implementation of project "Grain for Green" (Li et al., 2012), the grasslands in Inner Mongolia were greatly protected, and the grassland area was maintained at a stable level. In view of this development, this study disregarded the influence of the changes in grassland area.

The capacity of SOC sequestration and potential are related not only to vegetation but also to other factors, such as climate, environment and human activities. Based on meteorological data from 2000 to 2012 downloaded from the China Data Sharing Service Network (http://cdc.cma.gov.cn/), we analyzed the correlations between SOC storage and major meteorological factors (i.e. relative humidity, rainfall, sunlight radiation duration and air temperature). The results showed that SOC storage was significantly correlated with relatively humidity and rainfall from May to September (Fig. 6).
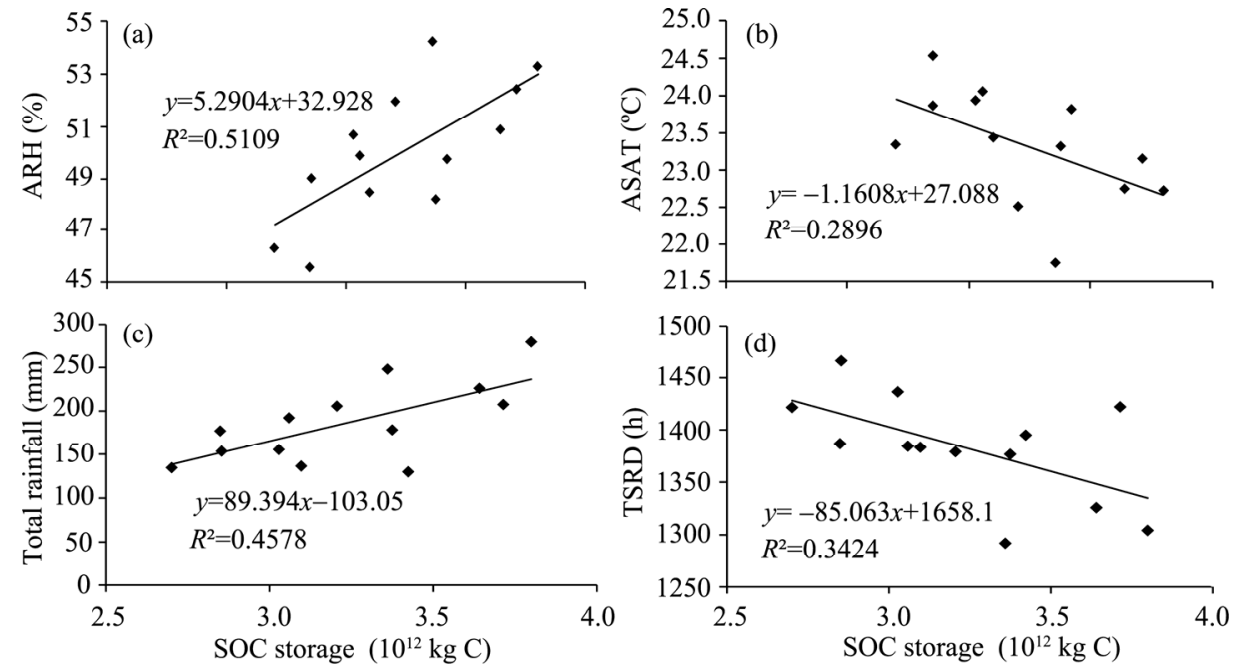

Fig. 6 Relationships of SOC storage with (a) average relatively humidity (ARH), (b) average surface air temperature (ASAT), (c) total rainfall and (d) total sunlight radiation duration (TSRD) from May to September during the period 2000-2012

In addition, human factors, such as grazing intensity and enclosure measurement, could influence SOC storage. Since the end of the $20^{\text {th }}$ century, numerous measures, such as increasing the enclosure area and prohibiting grazing, have been intensified in Inner Mongolia, which simultaneously promoted the accumulation of SOC (Fu et al., 2011). Land use and land cover changes (particularly the agricultural land) can also influence SOC storage (Ogle et al., 2005). The interaction between soil and environments frequently occurs under the influence of these factors. Therefore, the inter-influence between these factors and SOC storage should be investigated to accurately estimate the SOC storage and potential. Furthermore, SOC storage would also change dynamically at different times of a year. Change in the content of carbon dioxide in the atmosphere also affects SOC storage.

The changes of SOC storage and potential involved a process of long-term fluctuation and showed concurrent changes along with the variations of environmental factors. The results 
indicated that the SOC storage in 2000-2012 tended to increase in general. The results of other studies have also showed that climate change would affect SOC storage at large scale (Li et al., 2015), and the SOC loss in semi-arid environments induced by intensive land use was largely irreversible (Wiesmeier et al, 2015). Therefore, the mechanism of effects of long-term climate change on soil carbon accumulation in grasslands is still worthy of attention.

\section{Conclusions}

On the basis of 130 MODIS images from 2000 to 2012, combined with 195 soil samples and 195 vegetation samples collected in 2012, we studied on the SOC storage and potential of grasslands in central and eastern Inner Mongolia. From 2000 to 2012, the annual SOC storage of grasslands in the study area increased with fluctuations in general, and the annual changes varied among different grassland types. The SOC storage of grasslands in 2012 increased by $0.51 \times 10^{12} \mathrm{~kg} \mathrm{C}$ compared to that in 2000 . The annual average carbon sequestration rate was $0.04 \times 10^{12} \mathrm{~kg} \mathrm{C}$. The slope of the values of SOC storage showed that the SOC storage increased overall since 2000, specifically for the Hulun Buir grassland and Xilin Gol grassland, where the typical grassland type are mainly distributed. Taking the SOC storage under the best grassland quality between 2000 and 2012 as a reference, we predicted an SOC potential of $1.38 \times 10^{12} \mathrm{~kg} \mathrm{C}$. The SOC potential was large mainly in the eastern area and parts of the northwestern area. However, the SOC potential was relatively small in the central and southwestern regions.

\section{Acknowledgements}

This study was funded by the National Technology \& Science Support Program of China (2012BAD16B02). We gratefully acknowledge the valuable assistance of ZHANG Qingyu, GOU Linghui, HUANG Yu and CHENG Yu with the sample collection and experiments. We also thank two anonymous reviewers for their constructive comments and suggestions to improve this manuscript.

\section{References}

Batjes N H. 1996. Total carbon and nitrogen in the soils of the world. European Journal of Soil Science, 47(2): 151-163.

Carlson T N, Ripley D A. 1997. On the relation between NDVI, fractional vegetation cover, and leaf area index. Remote Sensing of Environment, 62(3): 241-252.

Chen Z Z, Wang S P. 2000. Typical Grassland Ecosystem of China. Beijing: Science Press, 1-5. (in Chinese)

Dai E F, Zai R X, Ge Q S, et al. 2014. Topsoil organic carbon storage and its changes in Inner Mongolia grassland from the 1980s to 2010s. Acta Geographica Sinica, 69(11): 1651-1660. (in Chinese)

Dai E F, Huang Y, Zhao D S. 2015. Review on soil carbon sequestration potential in grassland ecosystems. Acta Ecologica Sinica, 35(12): 3908-3918. (in Chinese)

Dong Y S, Zhang S, Qi Y C, et al. 2000. Fluxes of $\mathrm{CO}_{2}, \mathrm{CH}_{4}$ and $\mathrm{N}_{2} \mathrm{O}$ from a typical temperate grassland in Inner Mongolia and its daily variation. Chinese Science Bulletin, 45(17): 1590-1594.

Du Q L. 2006. Grassland Sustainable Development Strategy of China. Beijing: China Agriculture Press, 12-13. (in Chinese)

Friedlingstein P, Bopp L, Ciais P, et al. 2001. Positive feedback between future climate change and the carbon cycle. Geophysical Research Letters, 28(8): 1543-1546.

Fu Y F, Yu Y Q, Huang Y. 2011. Changes of soil organic carbon of grassland in the Xilinguole, Inner Mongolia from 2000 to 2007. Pratacultural Science, 28(9): 1589-1597. (in Chinese)

Gao Q Z, Li Y E, Wan Y F, et al. 2006. Grassland degradation in Northern Tibet based on remote sensing data. Journal of Geographical Sciences, 16(2): 165-173.

Grace J. 2004. Understanding and managing the global carbon cycle. Journal of Ecology, 92(2): 189-202.

Guo R, Wang X K, Lu F, et al. 2008. Soil carbon sequestration and its potential by grassland ecosystems in China. Acta Ecologica Sinica, 28(2): 862-867. (in Chinese)

Hu Y F, Yan Y, Yu G M, et al. 2012. The ecosystem distribution and dynamics in Xilingol League in 1975-2009. Scientia Geographica Sinica, 32(9): 1125-1130. (in Chinese)

Huang Y, Sun W J, Zhang W, et al. 2010. Review of the changes of soil organic carbon of terrestrial ecosystems in China: A mini-review. Science China Life Sciences, 53(7): 766-775. 
Jobbágy E G, Jackson R B. 2000. The vertical distribution of soil organic carbon and its relation to climate and vegetation. Ecological Applications, 10(2): 423-436.

Krogh L, Noergaard A, Hermansen M, et al. 2003. Preliminary estimates of contemporary soil organic carbon stocks in Denmark using multiple datasets and four scaling-up methods. Agriculture, Ecosystems \& Environment, 96(1-3): 19-28.

Lal R. 2004. Soil carbon sequestration to mitigate climate change. Geoderma, 123(1-2): 1-22.

Li C F, Zhang C, Luo G P, et al. 2015. Carbon stock and its responses to climate change in Central Asia. Global Change Biology, 21(5): 1951-1967.

Li C S, Frolking S, Frolking T A. 1992. A model of nitrous oxide evolution from soil driven by rainfall events: 1 . Model structure and sensitivity. Journal of Geophysical Research, 97(D9): 9759-9776.

Li H X. 2002. Assessment and zoning of hazard degree and analysis of development trend of soil erosion in Ya'an Region. Journal of Soil and Water Conservation, 16(6): 17-19. (in Chinese)

Li H X, Liu S Z. 2004. A model of grassland degradation assessment based on NDVI-Taking the grassland in Tibet as an example. Journal of Mountain Science, 21(Suppl.): 69-71. (in Chinese)

Li X H, Wei Y R, Zhang C H. 2012. Variation of grassland area and its cause in Inner Mongolia: a case study on Duolun County of Xilin Gol League. Pratacultural Science, 29(1): 19-24. (in Chinese)

Li X J. 2011. Estimation and dynamic change analysis of vegetation fractional coverage based on mixed-pixel unmixing model in the Loess Plateau. MSc Thesis. Xi'an: Northwest University. (in Chinese)

Liao G P, Jia Y L. 1996. Chinese Grassland Resources. Beijing: China Science and Technology Press, 5-7. (in Chinese)

Liu J, Zhang Q, Li Y, et al. 2015. Effects of pasture management on soil fertility and microbial communities in the semi-arid grasslands of Inner Mongolia. Journal of Soils and Sediments, doi: 10.1007/s11368-015-1210-7.

Long S P, Moya E G, Imbamba S K, et al. 1989. Primary productivity of natural grass ecosystems of the tropics: a reappraisal. Plant and Soil, 115(2): 155-166.

Lu S, Meng P, Zhang J, et al. 2015. Changes in soil organic carbon and total nitrogen in croplands converted to walnut-based agroforestry systems and orchards in southeastern Loess Plateau of China. Environmental Monitoring and Assessment, 187(11): 1-9.

Luo Z, Wang E, Zheng H, et al. 2015. Convergent modeling of past soil organic carbon stocks but divergent projections. Biogeosciences Discussions, 12(5): 4245-4272.

Ma W H, Han M, Lin X, et al. 2006. Carbon storage in vegetation of grasslands in Inner Mongolia. Journal of Arid Land Resources and Environment, 20(3): 192-195. (in Chinese)

Molina J A E, Clapp C E, Shaffer M J, et al. 1983. NCSOIL, a model of nitrogen and carbon transformations in soil: Description, calibration and behavior. Soil Science Society of American Journal, 47(1): 85-91.

Mueller T, Jensen L S, Hansen S, et al. 1996. Simulating soil carbon and nitrogen dynamics with the soil-plant-atmosphere system model DAISY. In: Powlson D S, Smith P, Smith J U. Evaluation of Soil Organic Matter Models: Using Existing Long-term Datasets. Heidelberg: Springer-Verlag, 38: 275-281.

Ogle S M, Breidt F J, Paustian K. 2005. Agricultural management impacts on soil organic carbon storage under moist and dry climatic conditions of temperate and tropical regions. Biogeochemistry, 72(1): 87-121.

Parton W J, Scurlock J M O, Ojima D S, et al. 1995. Impact of climate change on grassland production and soil carbon worldwide. Global Change Biology, 1(1): 13-22.

Piñeiro G, Paruelo J M, Oesterheld M, et al. 2010. Pathways of grazing effects on soil organic carbon and nitrogen. Rangeland Ecology \& Management, 63(1): 109-119.

Purevdorj T S, Tateishi R, Ishiyama T, et al. 1998. Relationships between percent vegetation cover and vegetation indices. International Journal of Remote Sensing, 19(18): 3519-3535.

Qiu J J, Tang H J, Li C S. 2003. Study on the situation of soil organic carbon storage in ecotone between agriculture and animal husbandry-A case study from Inner Mongolia. Chinese Journal of Eco-Agriculture, 11(4): 86-88. (in Chinese)

Schils R, Kuikaman P, Liski J, et al. 2008. Review of existing information on the interrelations between soil and climate change. ClimSoil, 1-208. [2008-12-16]. http://ec.europa.eu/environmtnt/soil/pdf/climsoil_report_dec_2008.pdf.

Schimel D S, House J I, Hibbard K A, et al. 2001. Recent patterns and mechanisms of carbon exchange by terrestrial ecosystems. Nature, 414(6860): 169-172.

Scurlock J M O, Hall D O. 1998. The global carbon sink: a grassland perspective. Global Change Biology, 4(2): $229-233$.

Sombroek W G, Nachtergaele F O, Hebel A. 1993. Amounts, dynamics and sequestering of carbon in tropical and subtropical soils. Ambio, 22(7): 417-426.

Song Y, Ma M G. 2007. Study on vegetation cover change in Northwest China based on SPOT VEGETATION data. Journal of Desert Research, 27(1): 89-93. (in Chinese) 
Stow D, Daeschner S, Hope A, et al. 2003. Variability of the seasonally integrated normalized difference vegetation index across the north slope of Alaska in the 1990s. International Journal of Remote Sensing, 24(5): 1111-1117.

Wen L, Dong S K, Zhu L, et al. 2010. The construction of grassland degradation index for alpine meadow in Qinghai-Tibetan Plateau. Procedia Environmental Sciences, 2: 1966-1969.

Wiesmeier M, Munro S, Barthold F, et al. 2015. Carbon storage capacity of semi - arid grassland soils and sequestration potentials in Northern China. Global Change Biology, 21(10): 3836-3845.

Wu G C, Zhou Z X, Xiao W F, et al. 2012. Dynamic monitoring of vegetation coverage in three gorges reservoir area based on MODIS NDVI. Scientia Silvae Sinicae, 48(1): 22-28. (in Chinese)

Xu Z. 2004. The Manual of Chinese Pasture. Beijing: Chemical Industry Press, 7. (in Chinese)

Yang Z F, Xia X Q, Yu T, et al. 2012. Soil carbon pool in the northeast Inner Mongolia and its influencing factors. Earth Science Frontiers, 18(6): 1-10. (in Chinese)

Zhao D, Wu S, Dai E, et al. 2015. Effect of climate change on soil organic carbon in Inner Mongolia. International Journal of Climatology, 35(3): 337-347.

Zou Y R, Zhang Z X, Zhou Q B, et al. 2002. Analysis of grassland dynamic in China based on RS and GIS. Resources Science, 24(6): 42-47. (in Chinese) 